\title{
Cervical Pessary Plus Progesterone for Twin Pregnancy with Short Cervix Compared to Unselected and Non-Treated Twin Pregnancy: A Historical Equivalence Cohort Study (EPM Twin Pessary Study)
}

\section{Pessário cervical associado a progesterona em gestações gemelares com colo curto comparado a gestações gemelares não selecionadas e não tratadas: estudo de coorte histórica de equivalência (Estudo de Pessário em Gêmeos EPM)}

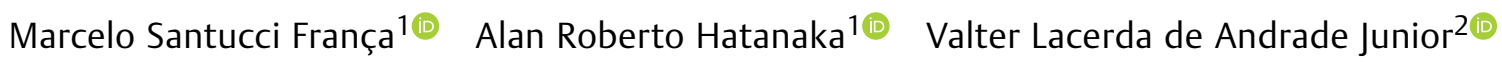
Julio Elito Junior ${ }^{10}$ David Baptista Silva Pares ${ }^{10}$ Tatiana Emy Nishimoto Kawanami Hamamoto ${ }^{10}$ Stephanno Gomes Pereira Sarmento ${ }^{1,3}$ Rosiane Mattar ${ }^{10}$ Antonio Fernandes Moron ${ }^{10}$
\end{abstract}

\footnotetext{
${ }^{1}$ Obstetrics Department, Escola Paulista de Medicina, Universidade Federal de São Paulo, São Paulo, SP, Brazil

2 Postgraduate Department, Faculdade Impacta, São Paulo, SP, Brazil

${ }^{3}$ Obstetrics and Gynecology Department, Faculdade de Medicina de Jundiaí, Jundiaí, SP, Brazil
}

Rev Bras Ginecol Obstet 2020;42(10):621-629.

\begin{abstract}
Keywords

- preterm birth

- cervical pessary

- dichorionicdiamniotic twin pregnancy

- short cervix

- vaginal progesterone

Objective The present study aims to determine if the use of cervical pessary plus progesterone in short-cervix $(\leq 25 \mathrm{~mm})$ dichorionic-diamniotic (DC-DA) twin pregnancies is equivalent to the rate of preterm births (PBs) with no intervention in unselected DC-DA twin pregnancies.

Methods A historical cohort study was performed between 2010 and 2018, including a total of 57 pregnant women with DC-DA twin pregnancies. The women admitted from 2010 to $2012(n=32)$ received no treatment, and were not selected by cervical length (Non-Treated group, NTG), whereas those admitted from 2013 to $2018(n=25)$, were routinely submitted to cervical pessary plus progesterone after the diagnosis of short cervix from the 18th to the 27 th weeks of gestation (Pessary-Progesterone group, PPG). The primary outcome analyzed was the rate of PBs before 34 weeks.

Results There were no statistical differences between the NTG and the PPG regarding $\mathrm{PB}<34$ weeks ( $18.8 \%$ versus $40.0 \%$ respectively; $p=0.07$ ) and the mean birthweight of the smallest twin $(2,037 \pm 425 \mathrm{~g}$ versus $2,195 \pm 665 \mathrm{~g} ; p=0.327)$. The Kaplan-Meyer Survival analysis was performed, and there were no differences between the groups before 31.5 weeks. Logistic regression showed that a previous PB ( $<37$ weeks) presented an odds ratio (OR) of 15.951 (95\% confidence interval [95\%Cl]: 1.294-196.557; $p=0.031^{*}$ ) for $\mathrm{PB}<34$ weeks in the PPG.
\end{abstract}

Address for correspondence Marcelo Santucci França, MD, Rua Botucatu, 740, Vila Clementino, São Paulo, SP, 04023-062, Brazil (e-mail: marcelosantucci.franca@gmail.com). received

March 11, 2020

accepted

May 18, 2020
DOI https://doi.org/ 10.1055/s-0040-1713806. ISSN 0100-7203.
Copyright (@) 2020 by Thieme Revinter

Publicações Ltda, Rio de Janeiro, Brazil
License terms

(c) (i) 


\section{Resumo}

\author{
Palavras-chave \\ - parto pré-termo \\ - pessário cervical \\ - gestação gemelar \\ dicoriônica- \\ diamniótica \\ - colo curto \\ - progesterona \\ vaginal
}

Conclusion In DC-DA twin pregnancies with a short cervix, (which means a higher risk of $\mathrm{PB}$ ), the treatment with cervical pessary plus progesterone could be considered equivalent in several aspects related to PB in the NTG, despite the big difference between these groups.

Objetivo Este estudo tem como objetivo determinar se o uso de pessário cervical associado a progesterona em gestações de gêmeos dicoriônicos-diamnióticos (DC-DAs) com colo do útero curto ( $\leq 25 \mathrm{~mm}$ ) apresenta taxa de parto prematuro (PP) equivalente à de gestações gemelares DC-DA sem nenhuma intervenção/não selecionadas.

Métodos Um estudo de coorte histórica foi realizado entre 2010 e 2018, incluindo um total de 57 mulheres grávidas com gestações gemelares DC-DA. As mulheres admitidas de 2010 a $2012(n=32)$ não receberam tratamento, e não foram selecionadas pelo comprimento cervical (grupo Não Tratado, GNT), enquanto as admitidas de 2013 a $2018(n=25)$ receberam pessário cervical rotineiramente associado a progesterona após o diagnóstico de colo curto entre a $18^{\mathrm{a}}$ e a $27^{\mathrm{a}}$ semanas de gestação (grupo Pessário-Progesterona, GPP). O desfecho primário analisado foi a taxa de PP antes de 34 semanas.

Resultados Não houve diferenças estatísticas entre o GNT e o GPP em relação ao $\mathrm{PP}<34$ semanas (respectivamente, $18,8 \%$ versus $40,0 \% ; p=0,07$ ) e ao peso médio ao nascer do gêmeo menor ( $2.037 \pm 425 \mathrm{~g}$ versus $2.195 \pm 665 \mathrm{~g} ; p=0,327)$. A análise de Kaplan-Meyer foi realizada, e não houve diferenças entre os grupos antes de 31,5 semanas. A regressão logística demonstrou que o nascimento prematuro anterior (< 37 semanas) apresentou razão de probabilidades (odds ratio, OR) de 15,951 (intervalo de confiança de $95 \%$ [IC95\%]: 1,294-196,557; $p=0,031^{*}$ ) para o nascimento prematuro $<34$ semanas no GPP.

Conclusão Em gêmeos DC-DA com colo uterino curto (o que significa maior risco de nascimento prematuro), o tratamento com pessário cervical associado a progesterona pode ser considerado equivalente em diversos aspectos relacionados à prematuridade no GNT, apesar da grande diferença entre os grupos.

\section{Introduction}

Despite the low prevalence of twin pregnancies (only 2\%), they are responsible for $15 \%$ of all spontaneous early preterm births (PBs) $<32$ weeks. The higher number of PBs probably occurs due to uterine overdistension. The rate of PBs in twin pregnancies $<37$ weeks is around $50 \%$, and the mean gestational age at delivery is around 36.5 weeks. ${ }^{1-3}$

A cervical length $<25 \mathrm{~mm}$ measured between 20 to 24 weeks in twin gestations is accepted as a good predictor for PB. A short cervix increases the risk of preterm birth before 28 weeks of gestation from $3.5 \%$ to $25.8 \%$, and from $41.2 \%$ to $75.5 \%$ before 37 weeks of gestation. ${ }^{4,5}$

Although the prediction is relatively well determined with short cervical length, the intervention is still a challenge in twin pregnancies. Different strategies for prevention of preterm delivery in twin pregnancies have been considered, such as vaginal progesterone, cervical pessary, and cervical cerclage. $^{6-8}$

A recent metanalysis ${ }^{9}$ of individual data concluded that vaginal progesterone in twin gestations with short cervix
$(<25 \mathrm{~mm}$ ) reduced the risk of PB before 33 weeks from $43.1 \%$ to $31.4 \%$ (relative risk [RR]: $0.69 ; 95 \%$ confidence interval [95\%CI]: 0.51-0.93), and reduced the risk of composite neonatal morbidity and mortality from $40 \%$ to $27.4 \%{ }^{10}$ (RR: 0.61; 95\%CI: 0.34-0.98), when compared with no treatment, but these results are not a consensus in literature. ${ }^{11,12}$ Another multicentric randomized controlled trials (RCT) in twins demonstrated that the prophylactic use of the cervical pessary could reduce the rate of early $\mathrm{PB}$ in the subgroup with a short cervix. Despite this evidence, the largest study ${ }^{13}$ using the cervical pessary in twin pregnancies did not demonstrate the benefits of its use.

In 2016, in New Jersey, a retrospective study ${ }^{8}$ compared the use of cervical cerclage to no treatment in twin pregnancies with short cervix $(<25 \mathrm{~mm})$, and significant results were obtained in favor of cerclage (odds ratio [OR]: 0.22; $95 \%$ CI: 0.058-0835), despite the fact that previous studies ${ }^{14} \mathrm{did}$ not corroborate this data.

Neither cerclage, the cervical pessary or progesterone could be considered a better choice for intervention in twin pregnancies with a short cervix, nor have they been 
discarded as an option for this particular type of pregnancy. ${ }^{15}$ But some studies observe favorable results in the pessary group after the comparison with progesterone (regarding PB and morbidity) in twin pregnancies with short cervix. ${ }^{16,17}$ Moreover, an economic analysis ${ }^{18}$ was published recently with positive results for the pessary group in twin pregnancies with a short cervix.

At the present moment, there is no publication comparing the use of the cervical pessary in twin gestations with a short cervix to low-risk dichorionic-diamniotic (DC-DA) twin pregnancies. The objective of the present study was to determine the equivalence of the use of the cervical pessary associated with progesterone in DC-DA twin gestations with a short cervix compared with no intervention in unselected twin pregnancies.

\section{Methods}

The present historical equivalence cohort study in asymptomatic DC-DA twin pregnancies was performed from January 2010 to July 2018 in Escola Paulista de Medicina, Universidade Federal de São Paulo, a public quaternary service in Brazil; it was approved by the Ethics Committee (under CAAE number 30873613.8.0000.5505; http://plataformabrasil.saude.gov.br/login.jsf), and was called the EPM Twin Pessary Study. From January 2013 to July 2018, after obtaining informed consent, we included in the study 25 women with cervical length $\leq 25 \mathrm{~mm}$ measured by transvaginal scan (Samsung Ultrasound System WS80A, Seongnam-si, Gyeonggi-do, South Korea), during gestational age between 18 to 27 weeks and 6 days (Pessary-Progesterone group, PPG). The PPG received 200-mg daily doses of vaginal micronized progesterone, and the Ingámed (Maringá, PR, Brazil) AM cervical pessary was placed (Figure B - Addendum), which is registered in the Brazilian Medical Regulatory Agency (Agência Nacional de Vigilância Sanitária, ANVISA, in Portuguese), under number $80086720036 .{ }^{19}$ Baseline characteristics and outcomes were compared with 32 DC-DA twin pregnancies from the same university from January 2010 to December 2012, neither selected by cervical length nor treated (Non-Treated group, NTG). The exclusion criteria for both groups were fetal malformation, selective fetal growth restriction, or refusal to sign the informed consent form. The exclusion criteria for the PPG were also exposed membranes, rupture of membranes, or labor.

For a description of the technique of the transvaginal cervical ultrasonography and the cervical pessary insertion, see the Addendum.

The primary outcome was defined as $\mathrm{PB}<34$ weeks. The secondary outcomes were defined as the mean gestational age at delivery ( \pm standard deviation), the mean weights of the biggest and smallest newborns, the comparison of the rate of $\mathrm{PB}<37,35,32$ and 28 weeks, the performance of consecutive deliveries during the study, the Kaplan-Meyer survival analysis, and the backward stepwise logistic regression for $\mathrm{PB}<34$ weeks for PPG.

Univariate logistic regression nor adjusted was performed for PPG considering in vitro fertilization (IVF), ethnicity (white/non-white), smoking, body mass index (BMI; > 30), maternal age ( $\geq 35$ years), gestational week at the inclusion in the study ( $>23$ weeks), previous $\mathrm{PB}$ ( $<37$ weeks), multiparity, and the PPG versus the NTG considering preterm birth $<34$ weeks.

The risk of $\mathrm{PB}<37$ weeks in both study groups was assessed using the Kaplan-Meyer Survival analysis. The consecutive gestational age deliveries compared both groups and evaluated the performance and the learning curve of groups during the study.

The continuous variables were expressed as medians and standard deviations, and the categorical variables were presented in numbers and percentages (\%). The comparison between the outcome groups was made using the Chisquared $\left(\mathrm{X}^{2}\right)$ test or the Mann-Whitney $U$ test for the categorical variables, and the Student $t$-test for the continuous variables. Significance was set at a $p$-value $<0.05$, two-tailed, and marked with an asterisk $\left(^{*}\right)$.

Using the primary outcome measure of $\mathrm{PB}<34$ weeks of gestation, with an effect size of $40 \%$ and an error level of $\alpha=0.5$, a sample size of 60 women (30 in each group) achieved a power of $72 \%$. For the analyses of the data, we used the Statistical Package for the Social Sciences (SPSS, IBM Corp., Armonk, NY, US) software, version 23.0, and Statplus (Mac v5 for Excel, AnalystSoft, Inc., Walnut, CA, US).

\section{Results}

\section{Demographic Characteristics}

In total, 57 women with DC-DA twin pregnancies participated in the study. Considering both groups, 40 (70.2\%) women were primigravidas, and 17 (29.8\%) were multiparous; 32 (56.1\%) were white, and 25 (43.9\%) were non-white. The differences between the groups are expressed in - Table 1 . For the PPG, the gestational age at the diagnosis varied between 18 and 27 weeks and 4 days (mean age of 24 weeks and 1 day \pm 2.4 weeks). The mean cervical length of these gestations at the time of the pessary placement was of $14.3 \pm 7.1 \mathrm{~mm}$.

\section{Outcomes}

\section{Parametric Comparison}

In our consecutive $(n=32)$ DC-DA twin pregnancy NTG, the mean gestational age at delivery was of $35.83 \pm 8.7$ weeks, and in the PPG $(n=25)$, it was of $34.59 \pm 2.72$ weeks $(p=0.11)$, a difference of only 1.24 weeks, despite the big difference between the groups regarding the risk of PB due to the short cervix. The mean interval of permanence of the cervical pessary was of $10.18 \pm 3.6$ weeks.

\section{Non-parametric Comparison}

\section{The Rate of Preterm Birth}

The comparison of the rate of PB between the PPG and NTG demonstrated the following perinatal results respectively: $<32$ weeks: $16 \%(4 / 25)$ versus $9.4 \%(3 / 32)(p=0.45)$; $<34$ weeks: $40.0 \%$ (10/25) versus $18.8 \%(6 / 32)(p=0.07) ;<35$ weeks: $44.0 \%$ 
Table 1 Demographic characteristics of the study sample

\begin{tabular}{|c|c|c|c|}
\hline Demographic characteristics & $\begin{array}{l}\text { Not-Treated } \\
\text { group }(n=32)\end{array}$ & $\begin{array}{l}\text { Pessary-Progesterone } \\
\text { group }(n=25)\end{array}$ & $p$-value \\
\hline Maternal age (years; \pm standard deviation) & $27.5 \pm 4.79$ & $35.2 \pm 4.07$ & $<0.0001^{*}$ \\
\hline Body mass index $(>30)$ & $9(28.1 \%)$ & $2(8.0 \%)$ & 0.27 \\
\hline In vitro fertilization & $10(42.9 \%)$ & $14(61.1 \%)$ & 0.41 \\
\hline Smoking & $2(6.2 \%)$ & $1(4.0 \%)$ & 0.76 \\
\hline Ethnicitys (white) & $15(46.8 \%)$ & $17(68.0 \%)$ & 0.06 \\
\hline Previous preterm birth & $3(9.4 \%)$ & $4(16.0 \%)$ & 0.42 \\
\hline Multiparity & $10(31.2 \%)$ & $8(32.0 \%)$ & 0.19 \\
\hline Week of inclusion & $17.94 \pm 5.83$ & $24.22 \pm 2.40$ & $<0.0001^{*}$ \\
\hline
\end{tabular}

Note: *Baseline characteristics of the study subjects (Student $t$-test for maternal age and week of inclusion; Chi-squared test for all other categorical variable). The asterisk (*) marks p-value statisticaly significant.

$(11 / 25)$ versus $28.1 \%(9 / 32)(p=0.21) ;<37$ weeks: $80.0 \%$ $(20 / 25)$ versus $50.0 \%(16 / 32)\left(p=0.02^{*}\right) ;<28$ weeks: no preterm delivery was registered in both groups.

\section{Comparison of Birthweight}

Regarding birthweigth for the smallest twin, the findings for the PPG and NTG were respectively: $2,038 \pm 426 \mathrm{~g}$ versus $2,195 \pm 665 \mathrm{~g}$, and they were not statistically significant $(p=0.327)$. For the heaviest twins, the difference was statistically significant $(2,148 \pm 434 \mathrm{~g}$ versus $2,493 \pm 643 \mathrm{~g}$; $p=0.028^{*}$ ). Furthermore, the use of the cervical pessary did not influence the birthweight difference between the bigger and smaller fetuses in each group. For the NTG, the mean difference was of $12 \pm 6 \%$; for the GPP, it was of $11 \pm 2 \%(p=0.375)$.

\section{Logistic Regression}

Univariate logistic regression nor adjusted was performed for PPG, and it considered maternal age ( $\geq 35$ years), ethnicity (white and non-white), BMI ( $>30$ ), smoking, week of inclusion in the study ( $<23$ weeks), IVF, previous $\mathrm{PB}(<37$ weeks), and multiparity, considering the number of deliveries $<34$ weeks as a dependent variable. A statistical difference was observed only for previous PB (OR: 15.951; 95\%CI: 1.294-

Table 2 Univariate logistic regression nor adjusted
196.557; $p=0.031^{*}$ ), as shown in - Table 2, and none of the other variables analyzed could be classified as relevant to determine $\mathrm{PB}<34$ weeks (Hosmer-Lemeshow Test; $p=0.08)$ (-Table 2).

\section{Cumulative Outcome and Learning Curve}

To analyze the performance of the PPG, the age at delivery of each case was plotted consecutively in the chart in - Fig. 1. The performance of the GPP in the middle of the consecutive analysis was decreasing, and, in the end, it presented a recovery (red curve). In comparison, the cervical length decreased continuously without a similar recovery (green curve). In contrast, the performance of the NTG was homogeneous, and was overlapping the 36th week during the whole period of the analysis (blue curve).

\section{Kaplan-Meyer Survival Analysis}

The cumulative percentage of participants who did not give birth spontaneously before 37 weeks was statistically significant between the two groups after the Kaplan-Meyer analysis. The median gestational age at delivery for the PPG was of 35.14 (95\%CI: 33.88-36.40) weeks, that is, slightly lower than that of the NTG (36.86 weeks; 95\%CI: 35.90-37.80), and it was

\begin{tabular}{|c|c|c|c|c|}
\hline All cases $(n=57)$ & Odds Ratio & $\begin{array}{l}\text { Inferior } 95 \% \\
\text { confidence interval }\end{array}$ & $\begin{array}{l}\text { Superior } 95 \% \\
\text { confidence interval }\end{array}$ & $p$-value \\
\hline $\begin{array}{l}\text { Pessary-Progesterone group } \\
\text { versus Non-Treated group }\end{array}$ & 0.243 & 0.043 & 1.368 & 0.109 \\
\hline Maternal age ( $\geq 35$ years) & 0.913 & 0.175 & 4.758 & 0.914 \\
\hline Ethnicity (white/non-white) & 1.316 & 0.309 & 5.607 & 0.71 \\
\hline Smoking & 1.116 & 0.138 & 9.016 & 0.918 \\
\hline Body mass index $(>30)$ & 1.212 & 0.186 & 7.912 & 0.841 \\
\hline Week of inclusion ( $<23$ weeks) & 3.038 & 0.622 & 14.844 & 0.17 \\
\hline In vitro fertilization & 1.153 & 0.281 & 4.732 & 0.843 \\
\hline Previous preterm birth ( $<37$ weeks) & 15.951 & 1.294 & 196.557 & $0.031^{*}$ \\
\hline Multiparity & 0.638 & 0.098 & 4.145 & 0.638 \\
\hline
\end{tabular}

Note: Univariate logistic regression nor adjusted considering the main maternal characteristics compared with the number of deliveries $<34$ weeks. The asterisk $\left(^{*}\right)$ marks $p$-value statistcaly significant. 


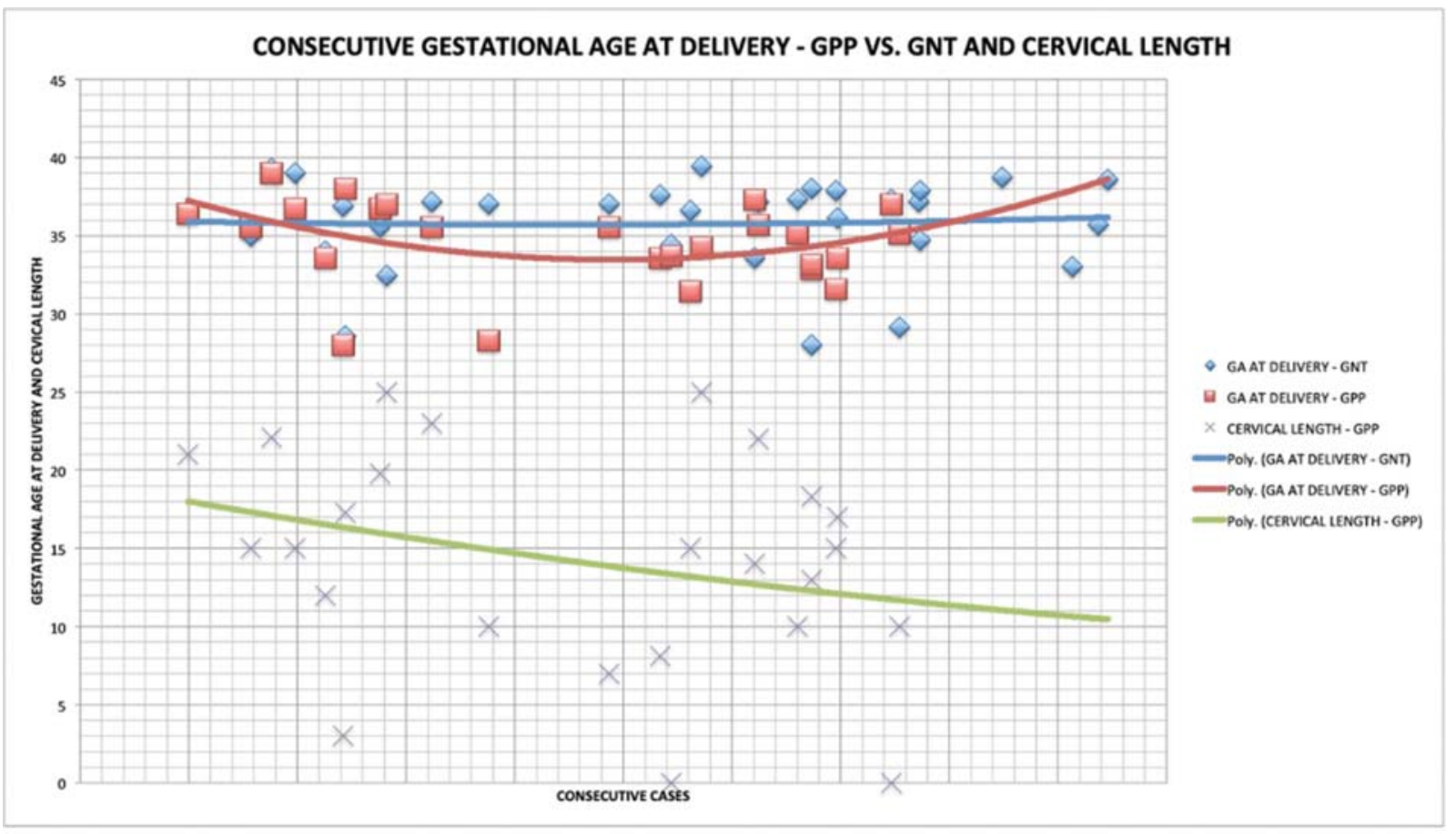

Fig. 1 Chart of consecutive twin pregnancies during the study. The blue dots represent the Non-Treated group (NTG) (blue line). The red dots represent the Pessary-Progesterone group (PPG) in the shape of a hyperbole (red line). The dots marked with an X (cervical length) represent the line without the shape of a hyperbole (green line).

statistically significant (Breslow [Generalized Wilcoxon]; $\left.p=0.025^{*}\right)$. Before 31.5 weeks, there was no difference between the groups, and the difference between them at 35 weeks, a landmark in twin pregnancies, was of $20 \%$ (black lines) after the Kaplan-Meyer survival analysis (-Fig. 2).

\section{Discussion}

The short cervix is a rare complication in human pregnancy, and only $1 \%$ to $2 \%$ of women have a cervix shorter than $25 \mathrm{~mm}$. Considering the prevalence of twin pregnancies as

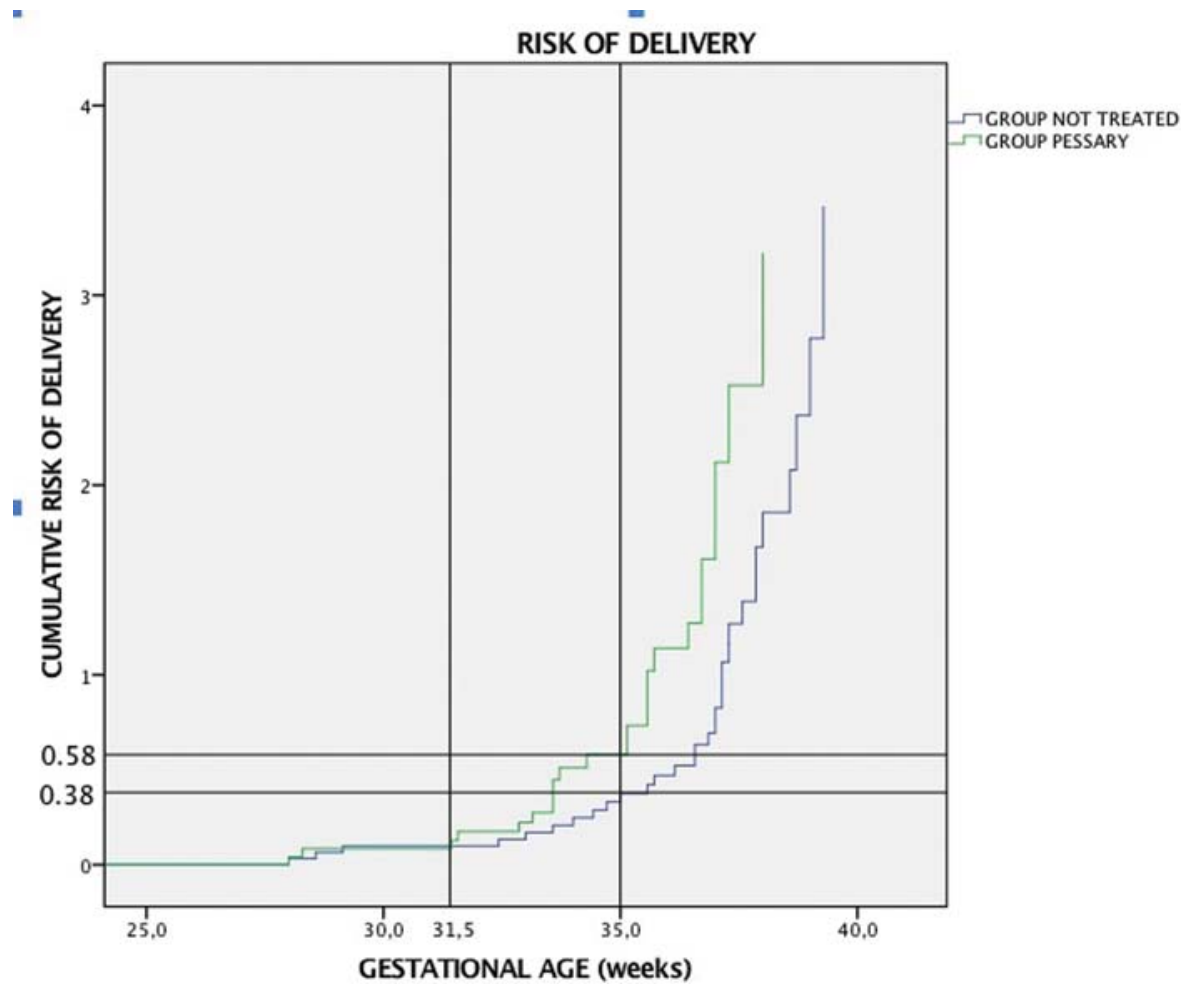

Fig. 2 Plot of the probability of continued pregnancy without delivery in the PPG (green) and NTG (blue) in the Kaplan-Meyer survival analysis (cumulative risk of delivery). 
$1 \%$ to $2 \%$, we can speculate that the prevalence of short cervices in twin pregnancies is extremely rare, $\sim 1$ to $2 /$ 10,000 gestations. For that reason, it is very probable that in the NTG there was a small number of women with short cervices, justifying the difference regarding this maternal characteristic between the groups. ${ }^{20,21}$

An important main finding of our study was the absence of difference in birthweight regarding the smaller twins of patients with short cervices when compared with the low risk for PB twin pregnancies. For the heavier twins, the difference was statistically significant, but they are less susceptible to an unfavorable outcome. The study sample had enough power to demonstrate the statistical difference between the biggest newborn presenting $\left(p=0.028^{*}\right)$, but that difference was not sustained on the smallest newborn $(p=0.327)$, although the sample had theoretical power to do so. This observation enables us to assume that regardless of the important difference between the groups regarding the risk of $\mathrm{PB}$, considering perinatal results for the smallest dichorionic twin, both groups are equivalent.

In the same way, there was only one variable with a statistically significant difference between the groups. In the univariate logistic regression, we could classify the variables relevant to $\mathrm{PB}$, and previous $\mathrm{PB}$ was the only important variable to determine $\mathrm{PB}<34$ weeks on PPG. The OR demonstrates odds almost 16 times higher of delivery $<34$ weeks if previous $\mathrm{PB}$ ( $<37$ weeks) was on the clinical history $\left(p=0.031^{*}\right)$. So, if previous PB is associated with a short cervix and a twin pregnancy, the risk of preterm delivery is so high that neither the cervical pessary nor vaginal progesterone will be enough to prevent it.

The Kaplan-Meyer analyses of the present study suggest that the differences between the groups were significant $\left(p=0.025^{*}\right)$; furthermore, analyzing the risk until 31.5 weeks, there was no difference in the cumulative risk in the survival analysis, and the biggest difference between the groups was only 0.2 at 35 weeks, an important landmark on gestational age for twins (-Fig. 2). These numbers could be hopeful if we consider that the results of the association of twin pregnancies and short cervices without treatment, and of the cervical pessary with progesterone, could be an alternative in rare cases with this association to reach better outcomes in twin pregnancies, corroborating the data of the ProTwin Study. ${ }^{22,23}$

In a recent randomized clinical trial ${ }^{24}$ from Egypt, ElRefaie et al analyzed the outcome of twin pregnancies with short cervices after the administration of placebo or vaginal progesterone. We could compare the results of the aforementioned study (progesterone and controls) with those of the present study. The rate of $\mathrm{PB}<34$ weeks was of $40 \%$ (PPG) versus 35\% (El-Refaie et al progesterone group) versus 52.8\% (El-Refaie et al controls); and the rate of $\mathrm{PB}<32$ weeks was of $16 \%$ (PPG) versus $12 \%$ (El-Refaie et al progesterone group) versus 29.6\% (El-Refaie et al controls).

The percentages of PB are similar for the PPG and the ElRefaie et al progesterone group, but when compared with the El-Refaie et al controls, the performance of the PPG was superior in both gestational ages. We must consider that these results from the El-Refaie et al progesterone group were not reproducible in the most relevant studies in twin pregnancies treated with isolated progesterone, and some articles even demonstrated that intramuscular progesterone could increase PB in twin pregnancies more intensely $<32$ weeks. $^{10,25-31}$

We can consider that the cervical pessary plus progesterone may have a better performance in the protection against $\mathrm{PB}$ in twin pregnancies compared with isolated progesterone, especially $<32$ weeks, as our data indicated a similar performance on the Kaplan-Meyer survival analysis $(<31.5$ weeks).

A weakness of the methodology employed in the present study is the demographic characteristics demonstrating that the groups were comparable except for maternal age and gestational age at inclusion; it is a potential risk of bias. Older maternal age is more frequently pointed out as a variable associated with $\mathrm{PB}$, but in our cohort, regarding this characteristic, it is statistically different. There were more older pregnant women in the PPG, which is a clear factor to increase the risk on that population, despite this statistical difference in demographic characteristics. All of these factors clearly increased the risk of PB in the PPG. However, surprisingly, the PPG demonstrated similar results in the prevention of prematurity, and the intervention was probably the reason for that.

Another potential risk of bias is that the gestational age at inclusion was statistically significant, and the difference was of 6.28 weeks. As an inclusion criterion, all patients in the sample were between the 18th to 27 th weeks of gestation. This important difference is not so relevant as a risk of bias, because the NTG received no intervention; therefore had the inclusion occurred at any gestational age, there would have been no difference in the final results of the NTG.

Another weakness of this methodology is the difference regarding the cervical length, because the cervical length of the PPG must be much shorter than that of the NTG, and this characteristic was probably responsible for the worse performance of the PPG regarding PB. ${ }^{4}$

One strength of the present study could be the change in the rates of $\mathrm{PB}$ using a mechanical device, which has been demonstrated as secure, and with a low rate of fetal and maternal complications; due to the presence of the device, the patients described that they felt safer regarding the attachment to the cervix itself, and these data had not yet been described on the literature. ${ }^{32}$

Another strength of the methods herein employed was the application of transvaginal ultrasound after the insertion of the pessary. It was only because of the ultrasound that we were able to recognize patients with the pessary in a bad position; after the diagnosis, the device was repositioned in all of those cases. ${ }^{33,34}$

Our data also suggest that it was the relocation of the pessary in a bad position that was responsible for the better performance in individual rates of $\mathrm{PB}$ (red line) during the study, as demonstrated by the learning curve, even despite the reduction in cervical length (green line) ( - Fig. 1). This is important information, because medical experts could be more efficient in using this device. The learning curve can be 
enhanced through better prediction of the risk of PB during pregnancy, and sometimes by increasing rest, or treating with antibiotics if the cases are associated with amniotic fluid sludge or repositioning of cervical pessary when it is not correctly placed around the cervix. ${ }^{35,36}$

Due to the expertise of the team involved, there was a lower rate of unnecessary interventions, such as the unreasonable removal of the cervical pessary, probably because of fear of the unknown, which was very common in the first years of the study of the device in hospitals that were not familiarized with it.

The present is one of the first studies published with this new pessary developed in Brazil; it is very similar in shape to the Arabin (Dr. Arabin GmbH \& Co., Witten, Germany) pessary, and our staff in the present study started the research, in a single center, in 2012 after the study by Goya et al. ${ }^{33}$ The team involved in the present study is headed by two senior medical researchers who acquired, over the course of 7 years, a lot of experience in cervical pessaries by using them and analyzing our perinatal results (this was how our team acquired experience: with practice and aligned to the literature). ${ }^{33}$

The Brazilian pessary has three differences in comparison with the Arabin pessary: 1) the surface of the internal ring is not soft, producing a "grasping" effect on the cervix, and during the entire study (which involved around 200 cervical pessaries in women at different gestational ages and in singleton pregnancies), we did not have any problems to remove this pessary, and probably because of this structure we did not have any escape of the pessary after 1 week of insertion; all re-insertions or maneuvers for pessary reposition (when necessary) occurred at the first week after insertion; 2) it is made with a harder silicone if compared with the Arabin, but it is completely malleable and adaptable to the vagina. This non-soft silicone with tighter adherence to the cervix placed over the perineal muscles can improve resistance against the pressure exhorted on the cervix by the uterus; and 3 ) it is a single-size cervical pessary, and sometimes the adjustment is not easy, especially in multiparous women in whom the cervix is commonly larger than that of primigravidas.

More studies are necessary to evaluate the real efficacy of the cervical pessary plus progesterone on PB in DC/DA twin pregnancies, and new trials must be designed with this purpose. It is relevant for the success of the new studies to consider the appropriate training of the researchers regarding insertion and evaluation by ultrasound of the correct position of the pessary, which should completely involve the cervix, as well as the development of a protocol regarding the performance of the transvaginal ultrasound during routine prenatal appointments to ensure a better performance on the prevention of $\mathrm{PB}$.

In conclusion, the comparable birthweight of the smallest twin, the similar risk of preterm birth $<31.5$ weeks (by the Kaplan-Meyer survival analysis), the absence of statistical difference regarding important variables in the logistic regression, and the absence of statistical difference in the rate of $\mathrm{PB}<28,32,34$ and 35 weeks can suggest an equivalence between the NTG and the PPG concerning some important aspects, despite the big difference between these groups.

\section{Contributors}

All of the authors contributed with the project and the interpretation of the data, with the writing of the article, the critical review of the intellectual content, and with the final approval of the version to be published.

\section{Conflict of Interests}

The authors have no conflict of interests to declare.

\section{Acknowledgments}

We would like to thank Ingámed and Dr. Carlos Gilberto Almodin for offering without cost a part of the cervical pessaries used in this study. We would also like to thank the Health and Medical Equipment Division of Samsung Brazil for offering the WS80A ultrasound system we used to perform the exams during the study. We are also grateful to Mr. Rudolf Wiedemann for his support with the English version of the present article.

\section{References}

1 Cahill AG, Odibo AO, Caughey AB, Stamilio DM, Hassan SS, Macones $\mathrm{GA}$, et al. Universal cervical length screening and treatment with vaginal progesterone to prevent preterm birth: a decision and economic analysis. Am J Obstet Gynecol. 2010;202 (06):548.e1-548.e8. Doi: 10.1016/j.ajog.2009.12.005

2 Romero R, Dey SK, Fisher SJ. Preterm labor: one syndrome, many causes. Science. 2014;345(6198):760-765. Doi: 10.1126/science. 1251816

3 Jelenkovic A, Sund R, Yokoyama Y, Hur YM, Ullemar V, Almqvist C, et al. Birth size and gestational age in opposite-sex twins as compared to same-sex twins: An individual-based pooled analysis of 21 cohorts. Sci Rep. 2018;8(01):6300. Doi: 10.1038/s41598018-24634-2

4 Conde-Agudelo A, Romero R. Prediction of preterm birth in twin gestations using biophysical and biochemical tests. Am J Obstet Gynecol. 2014;211(06):583-595. Doi: 10.1016/j.ajog.2014. 07.047

5 Conde-Agudelo A, Romero R, Hassan SS, Yeo L. Transvaginal sonographic cervical length for the prediction of spontaneous preterm birth in twin pregnancies: a systematic review and metaanalysis. Am J Obstet Gynecol. 2010;203(02):128.e1-128.e12

6 Di Renzo GC, Giardina I, Clerici G, Brillo E, Gerli S. Progesterone in normal and pathological pregnancy. Horm Mol Biol Clin Investig. 2016;27(01):35-48. Doi: 10.1515/hmbci-2016-0038

7 Di Renzo GC, Cabero Roura L, Facchinetti F, Helmer H, Hubinont C, Jacobsson B, et al. Preterm labor and birth management: recommendations from the European Association of Perinatal Medicine. J Matern Fetal Neonatal Med. 2017;30(17):2011-2030. Doi: 10.1080/14767058.2017.1323860

8 Houlihan C, Poon LCY, Ciarlo M, Kim E, Guzman ER, Nicolaides KH. Cervical cerclage for preterm birth prevention in twin gestation with short cervix: a retrospective cohort study. Ultrasound Obstet Gynecol. 2016;48(06):752-756. Doi: 10.1002/uog.15918

9 Romero R, Conde-Agudelo A, El-Refaie W, Rode L, Brizot ML, Cetingoz E, et al. Vaginal progesterone decreases preterm birth and neonatal morbidity and mortality in women with a twin gestation and a short cervix: an updated meta-analysis of individual patient data. Ultrasound Obstet Gynecol. 2017;49(03): 303-314. Doi: 10.1002/uog.17397

10 Norman JE, Mackenzie F, Owen P, Mactier H, Hanretty K, Cooper S, et al. Progesterone for the prevention of preterm birth in twin pregnancy (STOPPIT): a randomised, double-blind, placebo-controlled study and meta-analysis. Lancet. 2009;373(9680):2034-2040. Doi: 10.1016/S0140-6736(09)60947-8 
11 van 't Hooft J, van der Lee JH, Opmeer BC, van WassenaerLeemhuis AG, van Baar AL, Bekedam DJ, et al. Pessary for prevention of preterm birth in twin pregnancy with short cervix: 3-year follow-up study. Ultrasound Obstet Gynecol. 2018;51(05): 621-628. Doi: 10.1002/uog.19029

12 Goya M, de la Calle M, Pratcorona L, Merced C, Rodó C, Muñoz B, et al; PECEP-Twins Trial Group. Cervical pessary to prevent preterm birth in women with twin gestation and sonographic short cervix: a multicenter randomized controlled trial (PECEPTwins). Am J Obstet Gynecol. 2016;214(02):145-152. Doi: 10.1016/j.ajog.2015.11.012

13 Nicolaides KH, Syngelaki A, Poon LC, De Paco Matallana C, Plasencia W, Molina FS, et al. Cervical pessary placement for prevention of preterm birth in unselected twin pregnancies: a randomized controlled trial. Am J Obstet Gynecol. 2016;214(01): 3.e1-3.e9. Doi: 10.1016/j.ajog.2015.08.051

14 Dor J, Shalev J, Mashiach S, Blankstein J, Serr DM. Elective cervical suture of twin pregnancies diagnosed ultrasonically in the first trimester following induced ovulation. Gynecol Obstet Invest. 1982;13(01):55-60. Doi: 10.1159/000299484

15 Multifetal gestations: twin, triplet, and higher-order multifetal pregnancies. Obstet Gynecol. 2016;128(04):131-146

16 Dang VQ, Nguyen LK, Pham TD, He YTN, Vu KN, Phan MTN, et al. Pessary compared with vaginal progesterone for the prevention of preterm birth in women with twin pregnancies and cervical length less than $38 \mathrm{~mm}$ : a randomized controlled trial. Obstet Gynecol. 2019;133(03):459-467. Doi: 10.1097/AOG.00000000 00003136

17 Fox NS, Gupta S, Lam-Rachlin J, Rebarber A, Klauser CK, Saltzman DH. Cervical pessary and vaginal progesterone in twin pregnancies with a short cervix. Obstet Gynecol. 2016;127(04):625-630. Doi: 10.1097/AOG.0000000000001300

18 Le KD, Nguyen LK, Nguyen LTM, Mol BWJ, Dang VQ. Cervical pessary vs vaginal progesterone for prevention of preterm birth in women with twin pregnancy and short cervix: economic analysis following randomized controlled trial. Ultrasound Obstet Gynecol. 2020;55(03):339-347. Doi: 10.1002/uog.20848

19 Loureiro Fernandes G, Sancovski M, Azadinho BR, Amaro ER, Castro P, Werner H. Visualization of cervical pessary on threedimensional ultrasound. Ultrasound Obstet Gynecol. 2020;55 (03):426-427. Doi: 10.1002/uog.20394

20 Iams JD, Goldenberg RL, Meis PJ, Mercer BM, Moawad A, Das A, et al; National Institute of Child Health and Human Development Maternal Fetal Medicine Unit Network. The length of the cervix and the risk of spontaneous premature delivery. N Engl J Med. 1996;334(09):567-572. Doi: 10.1056/NEJM199602293340904

21 Qin JB, Sheng XQ, Wang H, Chen GC, Yang J, Yu H, et al. Worldwide prevalence of adverse pregnancy outcomes associated with in vitro fertilization/intracytoplasmic sperm injection among multiple births: a systematic review and meta-analysis based on cohort studies. Arch Gynecol Obstet. 2017;295(03):577-597. Doi: 10.1007/s00404-017-4291-2

22 Tajik P, Monfrance M, van 't Hooft J, Liem SMS, Schuit E, Bloemenkamp KWM, et al. A multivariable model to guide the decision for pessary placement to prevent preterm birth in women with a multiple pregnancy: a secondary analysis of the ProTWIN trial. Ultrasound Obstet Gynecol. 2016;48(01):48-55. Doi: 10.1002/uog.15855

23 Liem SMS, Schuit E, van Pampus MG, van Melick M, MonFrance M, Langenveld J, et al. Cervical pessaries to prevent preterm birth in women with a multiple pregnancy: a per-protocol analysis of a randomized clinical trial. Acta Obstet Gynecol Scand. 2016;95 (04):444-451. Doi: 10.1111/aogs.12849
24 El-Refaie W, Abdelhafez MS, Badawy A. Vaginal progesterone for prevention of preterm labor in asymptomatic twin pregnancies with sonographic short cervix: a randomized clinical trial of efficacy and safety. Arch Gynecol Obstet. 2016;293(01):61-67. Doi: 10.1007/s00404-015-3767-1

25 Rode L, Klein K, Nicolaides KH, Krampl-Bettelheim E, Tabor A; PREDICT Group. Prevention of preterm delivery in twin gestations (PREDICT): a multicenter, randomized, placebo-controlled trial on the effect of vaginal micronized progesterone. Ultrasound Obstet Gynecol. 2011;38(03):272-280. Doi: 10.1002/uog.9093

26 Rouse DJ, Caritis SN, Peaceman AM, Sciscione A, Thom EA, Spong CY, et al; National Institute of Child Health and Human Development Maternal-Fetal Medicine Units Network. A trial of 17 alphahydroxyprogesterone caproate to prevent prematurity in twins. $\mathrm{N}$ Engl J Med. 2007;357(05):454-461. Doi: 10.1056/nejmoa070641

27 Brizot ML, Hernandez W, Liao AW, Bittar RE, Francisco RPV, Krebs VLJ, et al. Vaginal progesterone for the prevention of preterm birth in twin gestations: a randomized placebo-controlled doubleblind study. Am J Obstet Gynecol. 2015;213(01):82.e1-82.e9. Doi: 10.1016/j.ajog.2015.02.021

28 Senat MV, Porcher R, Winer N, Vayssière C, Deruelle P, Capelle M, et al; Groupe de Recherche en Obstétrique et Gynécologie. Prevention of preterm delivery by 17 alpha-hydroxyprogesterone caproate in asymptomatic twin pregnancies with a short cervix: a randomized controlled trial. Am J Obstet Gynecol. 2013;208(03): 194.e1-194.e8. Doi: 10.1016/j.ajog.2013.01.032

29 Lim AC, Schuit E, Bloemenkamp K, Bernardus RE, Duvekot JJ, Erwich JJHM, et al. $17 \alpha$-hydroxyprogesterone caproate for the prevention of adverse neonatal outcome in multiple pregnancies: a randomized controlled trial. Obstet Gynecol. 2011;118(03): 513-520. Doi: 10.1097/AOG.0b013e31822ad6aa

30 Serra V, Perales A, Meseguer J, Parrilla JJ, Lara C, Bellver J, et al. Increased doses of vaginal progesterone for the prevention of preterm birth in twin pregnancies: a randomised controlled double-blind multicentre trial. BJOG. 2013;120(01):50-57. Doi: 10.1111/j.1471-0528.2012.03448.x

31 Brubaker SG, Pessel C, Zork N, Gyamfi-Bannerman C, Ananth CV. Vaginal progesterone in women with twin gestations complicated by short cervix: a retrospective cohort study. BJOG. 2015;122(05): 712-718. Doi: 10.1111/1471-0528.13188

32 Cruz-Melguizo S, San-Frutos L, Martínez-Payo C, Ruiz-Antorán B, Adiego-Burgos B, Campillos-Maza JM, et al. Cervical pessary compared with vaginal progesterone for preventing early preterm birth a randomized controlled trial. Obstet Gynecol. 2018;132 (04):907-915. Doi: 10.1097/AOG.0000000000002884

33 Goya M, Pratcorona L, Higueras T, Perez-Hoyos S, Carreras E, Cabero L. Sonographic cervical length measurement in pregnant women with a cervical pessary. Ultrasound Obstet Gynecol. 2011; 38(02):205-209. Doi: 10.1002/uog.8960

34 Mendoza Cobaleda M, Ribera I, Maiz N, Goya M, Carreras E. Cervical modifications after pessary placement in singleton pregnancies with maternal short cervical length: 2D and 3D ultrasound evaluation. Acta Obstet Gynecol Scand. 2019;98(11): 1442-1449. Doi: 10.1111/aogs.13647

35 Hatanaka AR, Mattar R, Kawanami TEN, Franca MS, Rolo LC, Nomura RMY, Araujo Jr E, et al. Amniotic fluid "sludge" is an independent risk factor for preterm delivery. J Matern Fetal Neonatal Med. 2014;29(01):120-125. Doi: 10.3109/14767058.2014.989202

36 Hatanaka AR, Franca MS, Hamamoto TENK, Rolo LC, Mattar R, Moron AF. Antibiotic treatment for patients with amniotic fluid "sludge" to prevent spontaneous preterm birth: A historically controlled observational study. Acta Obstet Gynecol Scand. 2019; 98(09):1157-1163. Doi: 10.1111/aogs.13603 


\section{Addendum}

\section{Patients and Methods}

The technique of transvaginal ultrasound for cervical measure

The transvaginal ultrasound cervical measure for inclusion was performed during the appointment of routine anomaly 2nd trimester scan and was used, by itself, to determine whether to place the pessary or not, with the cervical length between 0 to $25 \mathrm{~mm}$. Each transvaginal scan was performed over a period of about 10 minutes and the shortest of three measurements was considered. The exclusion criteria for GPP were the exposed membranes, rupture of membranes or labor.

All sonographers involved in this study obtained the appropriate Certificate of Competence for Cervical Assessment of The Fetal Medicine Foundation (https://courses. fetalmedicine.com).

After pessary insertion we performed transvaginal ultrasound during a regular monthly prenatal appointment to check the position of the pessary and evaluate funneling inside the pessary or suspicion of membranes protrusion.

\section{The technique of pessary insertion}

With a patient in gynecological position, sterile cervical pessary was folded in the middle and inserted in the vagina, it was unfolded after the insertion with the minor orifice involving the entire cervix, and the major orifice supported by the posterior vaginal wall. This insertion did not require any other equipment, besides sterile gloves and lidocaine gel to lubricate the distal part of the vagina and minimize the discomfort of the insertion. A digital vaginal examination was performed after the insertion to check the correct position of the device, and immediately after the clinical exam, a transvaginal ultrasound was performed with a similar intention. If the pessary was considered in a questionable position ( - Figure $\mathbf{C}$ - Addendum), some maneuvers to relocate the device were performed. These maneuvers consisted in pushing the pessary against the cervix, or

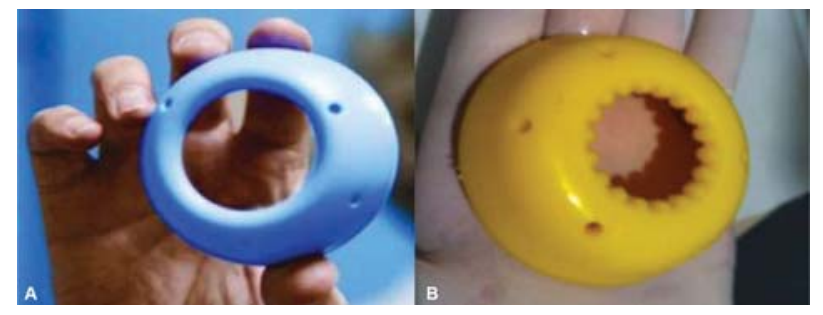

Fig. A/B Comparison between the Arabin cervical pessary (A) and the AM - Ingamed cervical pessary (B): they are similar regarding design, size and texture. The dimensions (largest lower diameter $\times$ smallest upper diameter $\times$ height) of the most frequently used Arabin pessary are $70 \times 32 \times 25 \mathrm{~mm}$, and of the Ingamed cervical pessary the dimensions are $70 \times 30 \times 25 \mathrm{~mm}$.

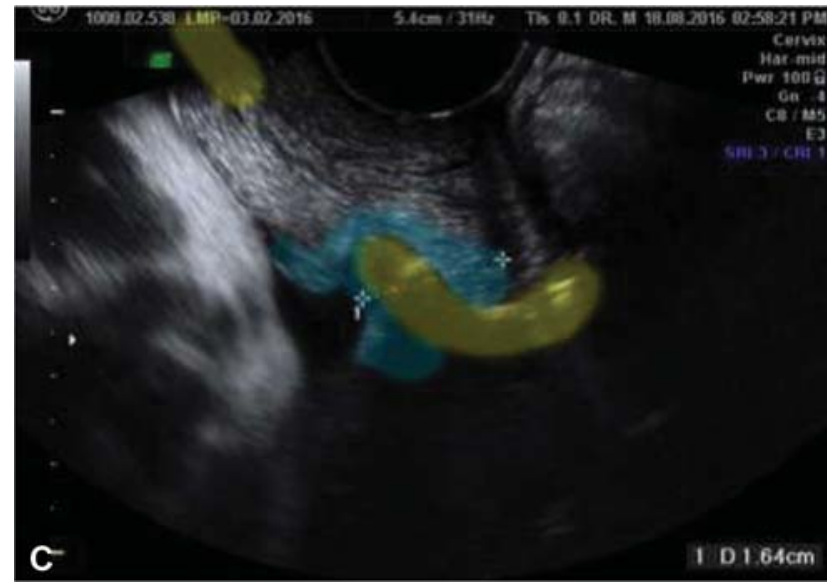

Fig. C Ultrasound image of short cervix not completely involved by cervical pessary (yellow area). It is important notice that posterior lip is not inside the pessary orifice (transversal section of pessary). Cervical gland area (CGAblue area) is not inside pessary; it was considered for our team in a questionably position and reposition was required.

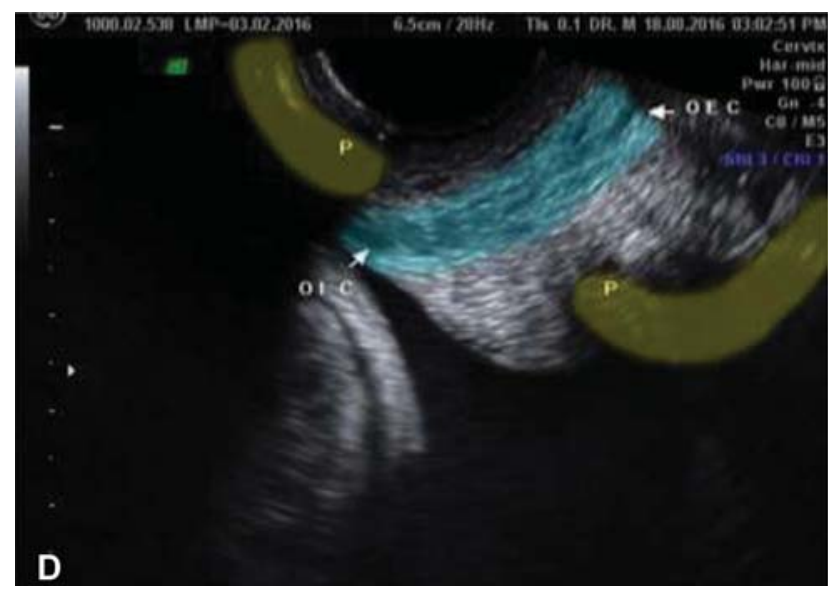

Fig. D Ultrasound image of short cervix completely involved by pessary (yellow area). It is relevant observe that CGA is centralized (blue area); it was considered for our team well positioned and no further procedures was required after this image. Both images are from the same patient, with difference a couple minutes ( 5 minutes difference between each image).

rotating the pessary to involve the entire cervix, or pushing the vaginal anterior wall to put the posterior lip of the cervix inside the pessary, or even a mix of these maneuvers (- Figure C/D - Addendum).

One week after pessary placement, we have performed transvaginal ultrasonography to identify the position of cervix concerning internal aperture of pessary. This is done to give us feedback on pessary placement. This feedback training us on placing the device as high as feasible and reduces inter-operator variability. This information is used to determine whether to reposition pessary if it is not completely involving the cervix ( $\sim$ Figure $\mathbf{D}$ - Addendum). 